\title{
Robotic Pyeloplasty: Step by Step Surgical Technique
}

\section{Abdullah Erdem Canda ${ }^{1 *}$, Ali Fuat Atmaca ${ }^{1}$ and Mevlana Derya Balbay ${ }^{2}$}

${ }^{1}$ Yildirim Beyazit University, School of Medicine, Ankara Ataturk Training \& Research Hospital, Department of Urology, Ankara, Turkey

${ }^{2}$ Memorial Sisli Hospital, Department of Urology, Istanbul, Turkey

\begin{abstract}
Uretero-pelvic junction obstruction (UPJO) leads to impaired transport of urine from the renal pelvis to the ureter and might lead to deterioration of renal function. Congenital causes, acquired factors and presence of an aberrant crossing vessel are the etiologic factors. Surgical correction is applied in the treatment of UPJO. Minimally invasive approaches including laparoscopic and robotic approaches are increasingly being performed. Robotic pyeloplasty is most frequently applied transperitoneally. The outcomes of robotic (transperitoneal and retroperitoneal), laparoscopic and open pyeloplasties seem to be similar due to the published literature. Robotic approach has the advantages of enabling quicker tissue dissection, reconstruction, intracorporeal suturing, antegrade double-J stenting and better ergonomics for the console surgeon. Although cost is an issue for robotic surgery, being a minimally invasive surgical approach with excellent functional and surgical outcomes are the advantages in addition to better cosmetic results for the patient. In this paper, surgical technique of robotic pyeloplasty is explained and outcomes of this approach are summarized by reviewing the literature.
\end{abstract}

Keywords: Robotic pyeloplasty; UPJ obstruction; Minimally invasive surgery; Surgical technique

\section{Introduction}

Uretero-pelvic junction (UPJ) obstruction leads to impaired transport of urine from the renal pelvis to the ureter that might cause increased pressure in the renal pelvis and deterioration of renal function. Etiology might include congenital causes, acquired factors such as infections, stones, trauma due to instrumentation leading to fibrosis and presence of an aberrant crossing vessel [1,2].

Symptoms and signs in adults might include recurrent flank pain, urinary tract infections and pyelonephritis that require surgical correction. Due to the European Association of Urology (EAU) Guidelines, indications for surgical treatment include impaired split renal function of less than $40 \%$, a decrease of split renal function of more than $10 \%$ in subsequent studies, increased antero-posterior diameter on abdominal ultrasound and grade III/IV dilatation of the renal pelvis [3]. It has been reported that, laparoscopic, retroperitoneoscopic and robotic approaches have similar success rates compared to open surgical approach in experienced centers [3].

\section{Surgical Technique}

Herein, the surgical technique that we apply is summarized. Surgical robotic pictures are obtained from the authors' own robotic surgical procedures.

\section{Patient positioning}

In the operating room, patient is positioned in the $60^{\circ}$ lateral decubitis position with proper paddings.

Port sites: We use open trocar insertion technique in our cases. Overall, 4 trocars are used (Figure 1). A $12 \mathrm{~mm}$ sized trocar for robotic camera is inserted into the abdominal cavity lateral to the rectus abdominis muscle at the level of the umbilicus. Intra-abdominal pressure is set to $15 \mathrm{~mm} \mathrm{Hg} \mathrm{CO}$. Following insertion of the $0^{\circ} 3 \mathrm{D}$ robotic camera into the abdominal cavity, an $8 \mathrm{~mm}$ sized robotic port is inserted under direct vision into the abdominal cavity located approximately $8 \mathrm{~cm}$ away from the camera port close to the costal arcus on the midclavicular line. A second $8 \mathrm{~mm}$ sized robotic port is inserted under direct vision approximately $8 \mathrm{~cm}$ away from the camera port close to the anterior superior iliac spine. These 3 ports form a triangle facing the kidney. A $10 \mathrm{~mm}$ sized assistant port is inserted into to abdominal cavity approximately located $4-5 \mathrm{~cm}$ lateral to the camera port for introducing sutures, suction, JJ stent and removing tissue cut portions.

\section{Surgical instruments used}

A mono-polar $8 \mathrm{~mm}$ Maryland curved scissors and a bipolar 8 $\mathrm{mm}$ Maryland forceps are used for the right and left robotic ports,

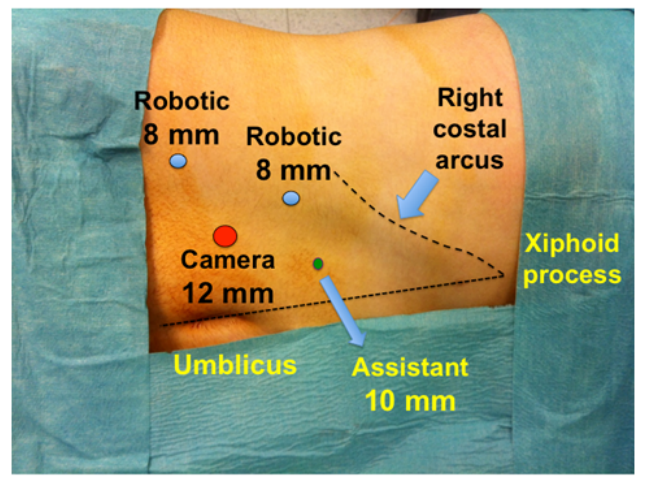

Figure1: Abdominal location of abdominal port sites (right side).

*Corresponding author: $\mathrm{Dr}$. Abdullah Erdem Canda Associate Professor of Urology, Yildirim Beyazit University, School of Medicine Ankara Ataturk Training \& Research Hospital, Department of Urology, Bilkent 06800 Ankara, Turkey, Tel: +90506-763-5466; Fax: +90-312-291-2525; E-mail: erdemcanda@yahoo.com

Received October 07, 2013; Accepted October 27, 2013; Published October 31, 2013

Citation: Canda AE, Atmaca AF, Balbay MD (2013) Robotic Pyeloplasty: Step by Step Surgical Technique. Adv Robot Autom 2: 111. doi: 10.4172/21689695.1000111

Copyright: (C) 2013 Canda AE, et al. This is an open-access article distributed under the terms of the Creative Commons Attribution License, which permits unrestricted use, distribution, and reproduction in any medium, provided the original author and source are credited. 
respectively. An endoscopic suction is used for irrigation and suction of intra-abdominal body fluids (urine and blood) and smoke. An endoscopic needle holder is used to introduce and remove suture materials into the abdominal cavity. An endoscopic grasper is used to remove tissue pieces such as excised UPJ section.

Following identification of the white line of Toldt, colon is identified and mobilized medially (Figure $2 \mathrm{a}$ and $2 \mathrm{~b}$ ). Thereafter, ureter is detected in the retroperitoneum and dissected off the surrounding structures (Figure 3a and 3b). Then, ureter is dissected up to the renal pelvis (Figure $4 \mathrm{a}-\mathrm{c}$ ). It is important to note and not to damage the presence of a crossing vessel that might exist in the retroperitoneum and that might cause UPJ obstruction, compressing the ureter and supplying the kidney (Figure 4a-4c). Renal pelvis is identified and fat tissue overlying the renal pelvis is dissected off. In most cases, renal pelvis appears quiet dilated and hydronephrotic (Figure 5).

(a)

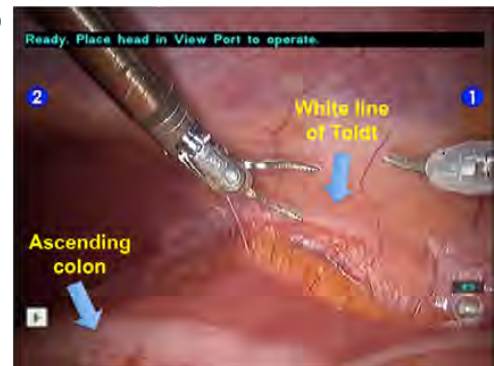

(b)

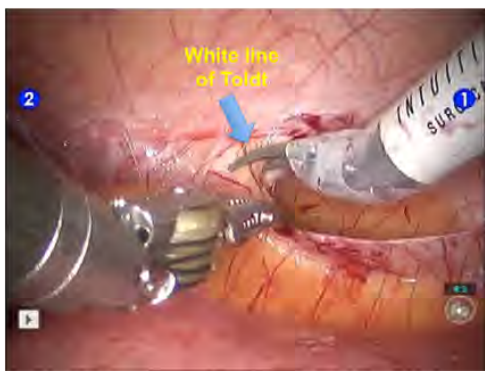

Figure 2: ( $a$ and $\mathbf{b})$ : Identification and incision of white line of Toldt and mobilization of the ascending colon.
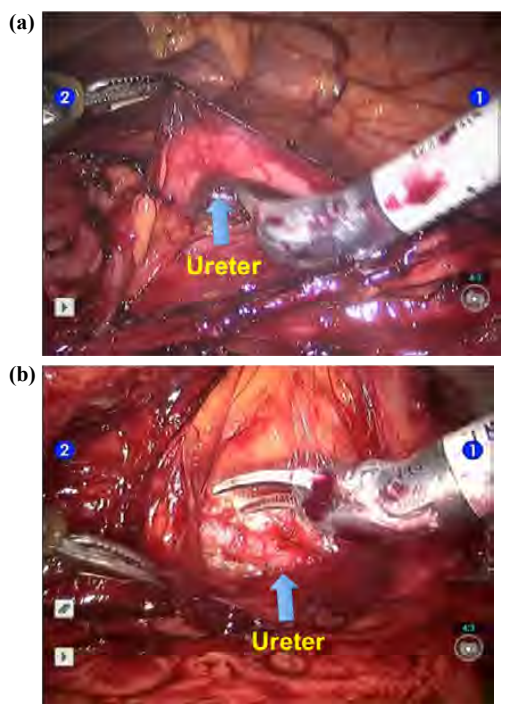

Figure 3: ( $\mathbf{a}$ and $\mathbf{b}$ ): Identification of the ureter in the retroperitoneum. (a)

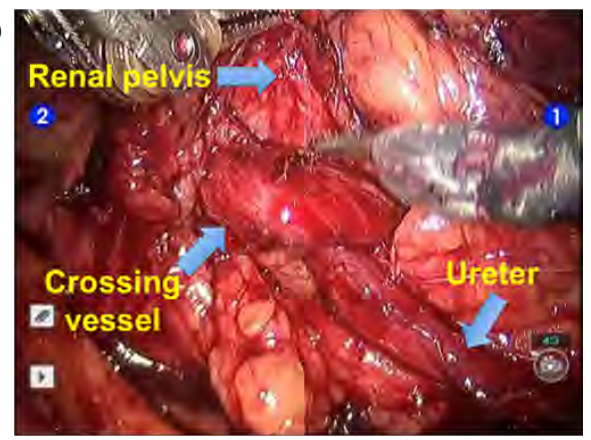

(b)

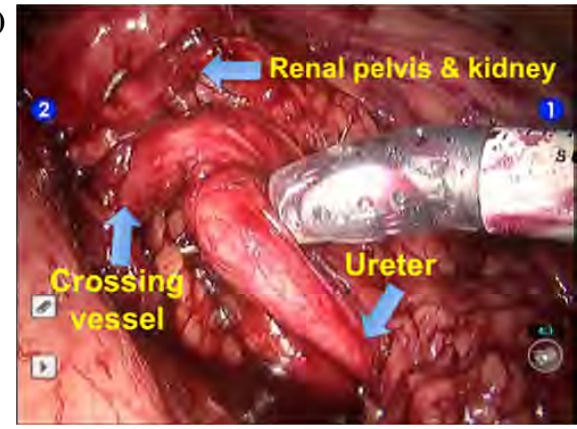

(c)

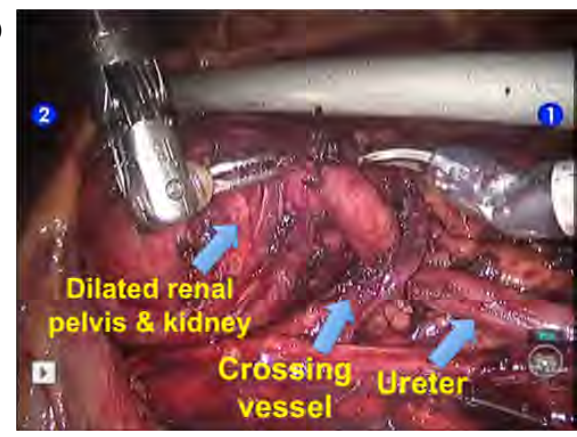

Figure 4: (a-c): Dissection of the ureter up to the renal pelvis and kidney. Note the crossing vessel compressing the uretero-pelvic junction.

A stitch by using $4 / 0$ vicrly suture with atraumatic needle is put on the anterior site of the upper ureter in order to mark the anterior surface (Figure 6). Then, ureter is cut above the suture completely (Figure 7). The obstructed UPJ tissue is excised and removed for histopatho logic investigation. Thereafter, ureter is spatulated at its cut end posteriorly (Figure 8). Dilated and hydronephrotic renal pelvis is cut and removed for histopathological evaluation (Figure 9a-9c). As a result, the size and capacity of the renal pelvis is reduced to its normal limits. Figure 10 shows the appearance of the prepared renal pelvis and ureter for anastomosis. A JJ stent is inserted through the $10 \mathrm{~mm}$ sized assistant port into the ureter (Figure 11a). Thereafter, anastomosis between the spatulated ureter and the renal pelvis is initiated starting from the posterior by using 4/0 vicrly suture with atraumatic RB-1 needle (Figure 11b). Excised renal pelvis is closed by using the same suture (Figure 12a and 12b). Finally, UPJ anastomosis is completed with preservation of the crossing vessel (Figure 13a and 13b).

Intra-abdominal pressure is dropped down to $5 \mathrm{~mm} \mathrm{Hg}$ and the surgical area is checked for bleeding. Following hemostasis, a drain is inserted into the abdominal cavity close to the operation field. Abdominal ports are removed under direct vision and port sites are closed. 
Citation: Canda AE, Atmaca AF, Balbay MD (2013) Robotic Pyeloplasty: Step by Step Surgical Technique. Adv Robot Autom 2: 111. doi: 10.4172/21689695.1000111

Page 3 of 5

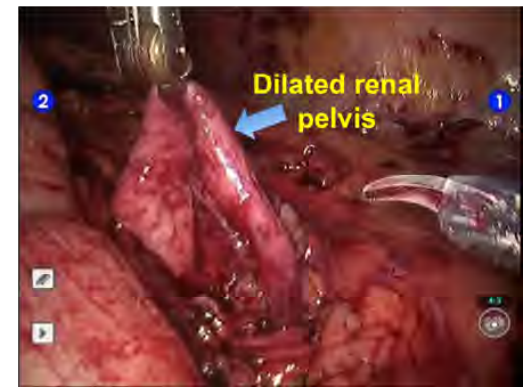

Figure 5: Dissection of dilated renal pelvis.

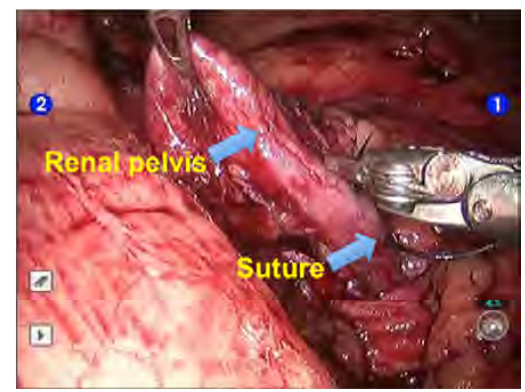

Figure 6: A stitch is put on the uretero-pelvic junction by using $4 / 0$ vicryl suture.

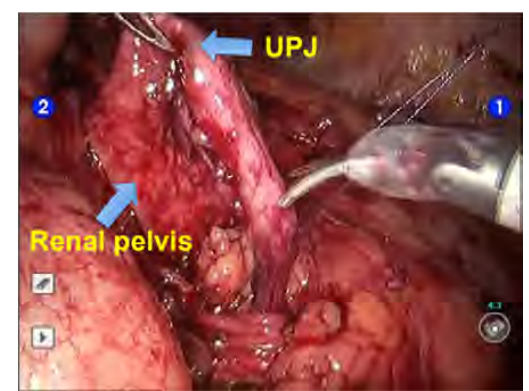

Figure 7: Ureter is cut just above the stitch. UPJ: Uretero-pelvic junction.

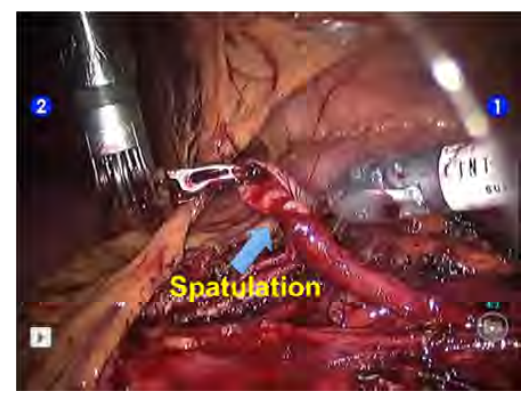

Figure 8: Ureter is spatulated.

Minimally invasive pyeloplasty including robotic and laparoscopic approaches were reported to have lower morbidity, shorter duration of hospital stay, and less blood loss compared with open surgical approach [4]. On the other hand, outcomes of both laparoscopic and robotic pyeloplasty approaches were reported to have durable with similar success rates in long term. Robotic approach was suggested having the advantages of enabling quicker tissue dissection, reconstruction, and intracorporeal suturing and antegrade double-J stenting for the console surgeon. Compared to laparoscopic approach, operating time was found to be decreased with better ergonomics for the surgeon in robotic approach [5]. Additionally, parent satisfaction was reported to be greater in robotic pyeloplasty than with open surgery regarding amount of cosmesis and recovery [6].

Table 1 summarizes selected series of the published robotic pyeloplasty literature with highest number of patients [7-14]. More than $95 \%$ success rates were reported by most series. Some of these series include both primary and secondary cases that might have an

(a)

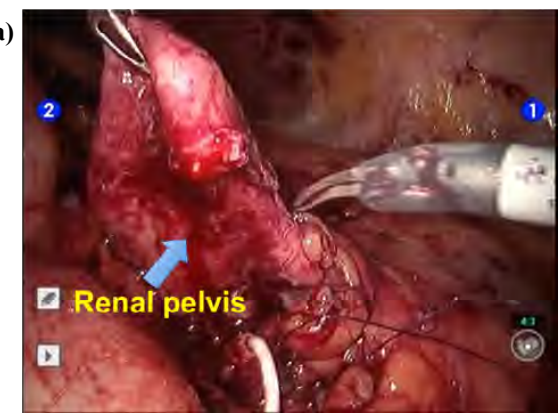

(b)

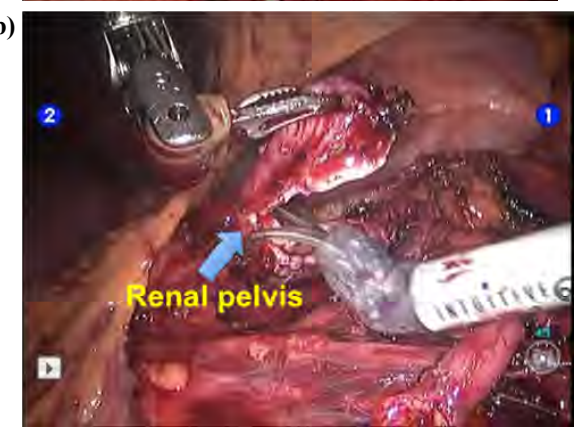

(c)

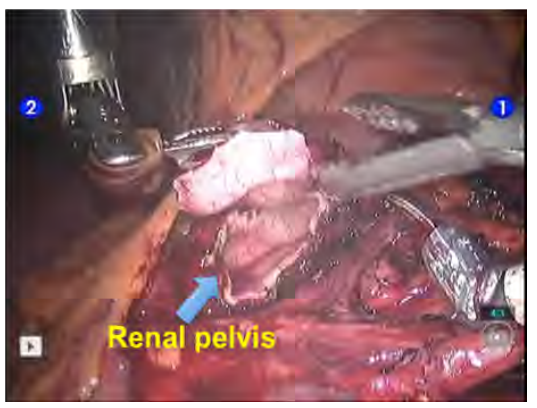

Figure 9: (a-c): Excision of the dilated renal pelvis.

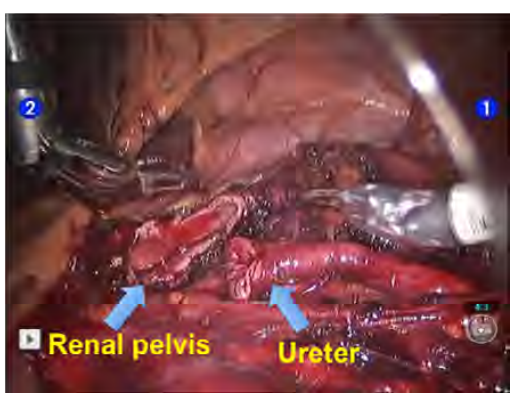

Figure 10: Appearance of spatulated ureter and renal pelvis following excision of the dilated part. 


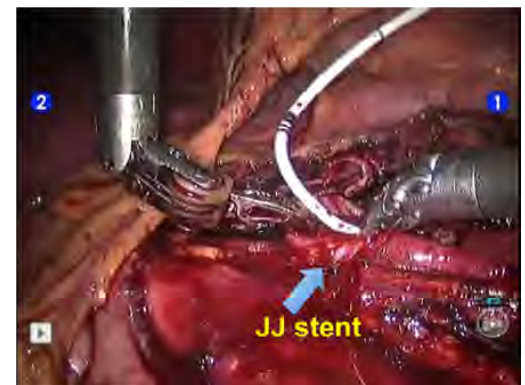

Figure 11a: Insertion of $\mathrm{JJ}$ stent into the ureter.

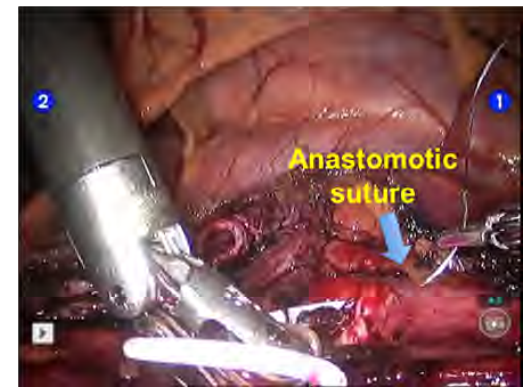

Figure 11b: Initiation of uretero-pelvic anastomosis by using $4 / 0$ atraumatic vicryl suture.

(a)

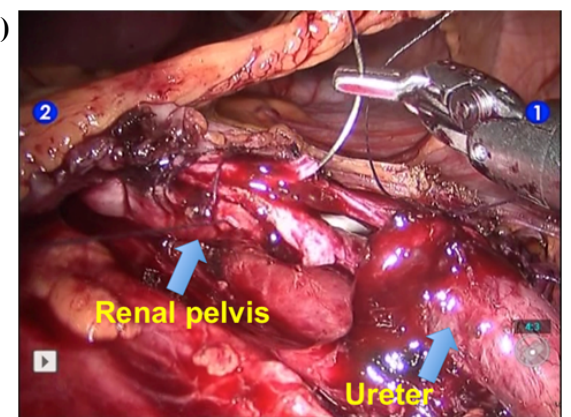

(b)

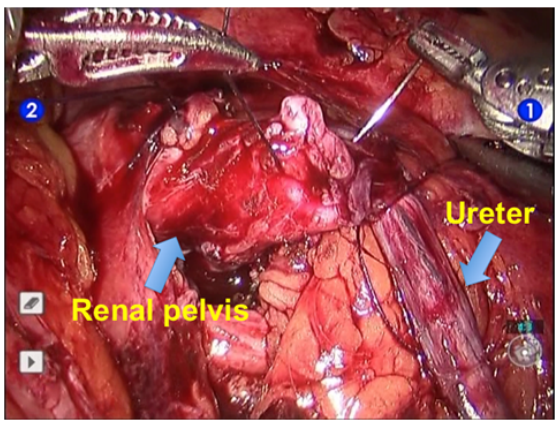

Figure 12: ( $a$ and $b)$ : Completion of the anastomosis.

impact on operation time [7-14]. Mean blood loss was less than 100 cc in most series [7-14]. Duration of hospital stay was between 1-2.5 days which is one of the main advantages minimally invasive surgery including laparoscopic approach [7-14].

Robotic laparoendoscopic single-site (LESS) pyeloplasty is one of the recently developing techniques that attract the attention of both urologists and patients. A number of reports exist in the literature related with this subject. It has been reported that robotic LESS pyeloplasty can be safely performed in selected patients with currently available robotic equipments [15]. Very recently; outcomes of 140 adult patients who underwent LESS were reported in a multi-institutional study [16]. Mean patient age was $39.9 \pm 15.7$ years. More than $90 \%$ of the patients underwent dismembered reconstructions. Mean operative time was $202.1 \pm 47$ minutes and estimated blood loss of was 61.2 $\pm 44.6 \mathrm{~mL}$. Robotic LESS surgery was performed in 31 patients. No patients required conversion to open surgery and no intraoperative complication occurred. Duration of hospital stay was $2.4 \pm 1.6$ days. Overall 90-day postoperative complication rate was reported to be $18.6 \%$. Of those, most were low-grade complications due to Clavien classification. More than $93 \%$ of the patients had symptoms resolved and more than $94 \%$ of the patients had radiologic improvement in UPJ obstruction after a mean follow-up of $14.0 \pm 10.8$ months.

Retroperitoneal robotic approach attracts interest having the advantage of avoiding transperitoneal access and possible problems related with transperitoneal approach. However, retroperitoneal space is limited compared to transperitoneal approach that might be a limiting factor for robotic surgery. Kaouk et al. evaluated feasibility of robotic dismembered pyeloplasty and concluded that this approach could be performed efficiently. Their surgical outcomes were detected to be comparable to published laparoscopic and transperitoneal robotic dismembered pyeloplasty series in adults [17]. Likewise, Cestari et al. evaluated the outcomes of 36 patients who underwent retroperitoneal robotic pyeloplasty and 19 underwent transperitoneal approach. The overall success rate was found to be $96 \%$. They concluded that robotic pyeloplasty performed either retroperitoneally or transperitoneally is a feasible and reproducible surgical approach [18].

Finally, cost is an important issue related with robotic surgery. Casella et al. evaluated the cost of robotic pyeloplasty [19]. They detected that operation time was significantly shorter in robotic approach compared to pure laparoscopy and no significant difference
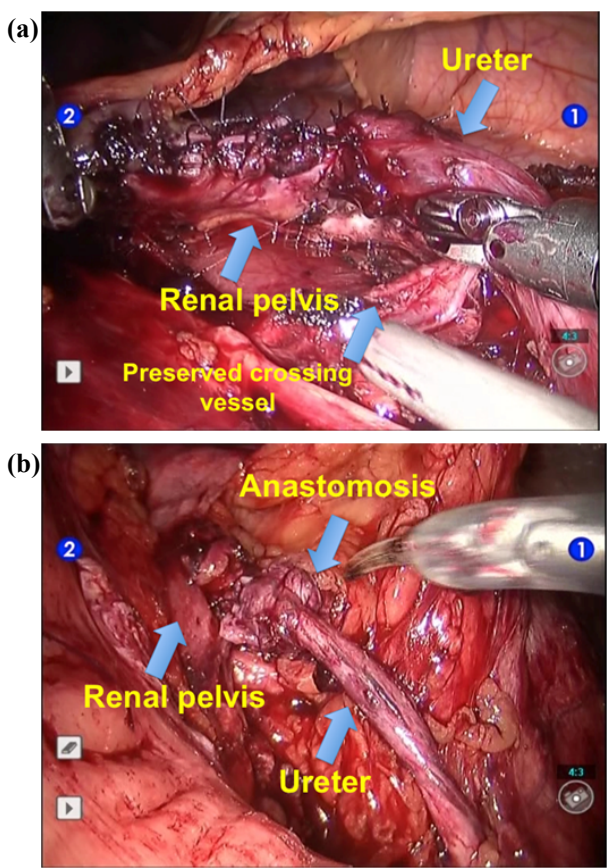

Figure 13: (a and b): Completed ureteropelvic anastomosis. 
Citation: Canda AE, Atmaca AF, Balbay MD (2013) Robotic Pyeloplasty: Step by Step Surgical Technique. Adv Robot Autom 2: 111. doi: 10.4172/21689695.1000111

Page 5 of 5

\begin{tabular}{|l|l|l|l|l|l|l|l|}
\hline Authors & Ref $\mathbf{N r}$ & Year & Number of patients & Mean operation time (min) & Mean blood loss & Duration of hospital stay & Success rate (\%) \\
\hline Patel & {$[7]$} & 2005 & 50 & 122 & 40 & 1.1 \\
\hline Minnillo et al. & {$[8]$} & 2011 & 155 & 198.5 & NR & 1.95 \\
\hline Gupta et al. & {$[9]$} & 2010 & 85 & 121 & 45 & 90 \\
\hline Lucas et al. & {$[10]$} & 2010 & 204 & 30 & 30 & NR \\
\hline Thom et al. & {$[11]$} & 2012 & 55 & 194 & 100 & 97 \\
\hline Niver et al. & {$[12]$} & 2012 & 119 & 218.7 & 62.8 & 1.7 \\
\hline Singh et al. & {$[13]$} & 2012 & 34 & 105 & 30 & 2.5 \\
\hline Sivaraman et al. & {$[14]$} & 2012 & 168 & 134.9 & 49 & NR \\
\hline
\end{tabular}

*NR: not reported

Table 1: Outcomes of selected published robotic pyeloplasty series.

was detected between the costs of two approaches [19]. On the other hand, Seideman et al. reported that robotic approach was associated with higher cost compared to laparoscopy [20].

\section{References}

1. Park JM, Bloom DA (1998) The pathophysiology of ureteropelvic junction obstruction. Urol Clin North Am 25: 161-169.

2. Grasso M, Caruso RP, Phillips CK (2001) UPJ obstruction in the adult population: are crossing vessels significant? Rev Urol 3: 42-51.

3. Tekgül S, Riedmiller H, Dogan HS, Hoebeke P, Kocvara R, et al. (2013) Nijman R, Radmayr Chr, Stein R. EAU Guidelines on Pediatric Urology.

4. Boylu U, Basatac C, Turan T, Onol FF, Gumus E (2012) Comparison of surgical and functional outcomes of minimally invasive and open pyeloplasty. $\mathrm{J}$ Laparoendosc Adv Surg Tech A 22: 968-971.

5. Hemal AK, Mukherjee S, Singh K (2010) Laparoscopic pyeloplasty versus robotic pyeloplasty for ureteropelvic junction obstruction: a series of 60 cases performed by a single surgeon. Can J Urol 17: 5012-5016.

6. Freilich DA, Penna FJ, Nelson CP, Retik AB, Nguyen HT (2010) Parental satisfaction after openversus robot assisted laparoscopic pyeloplasty: results from modified Glasgow Children's Benefit Inventory Survey. J Urol 183: $704-$ 708 .

7. Patel V (2005) Robot-asisted laparoscopic dismembered pyeloplasty. Urology 66: $45-49$.

8. Minnillo BJ, Cruz JA, Sayao RH, Passerotti CC, Houck CS, et al. (2011) Longterm experience and outcomes of robotic assisted laparoscopic pyeloplasty in children and young adults. J Urol 185: 1455-1460.

9. Gupta NP, Nayyar R, Hemal AK, Mukherjee S, Kumar R, et al. (2010) Outcome analysis of robotic pyeloplasty: a large single centre experience. BJU Int 105: 980-983.
10. Lucas SM, Sundaram CP, Leveillee RJ, Bird VG, Aziz M, et al. (2010) Laparoscopic and robotic pyeloplasty collaborative group: analysis of factors influencing success in 800 patients. J Endourol 24: A31-A32.

11. Thom MR, Haseebuddin M, Roytman TM, Benway BM, Bhayani SB, et al. (2012) Robot-assisted pyeloplasty: outcomes for primary and secondary repairs, a single institution experience. Int Braz J Urol 38: 77-83.

12. Niver BE, Agalliu I, Bareket R, Mufarrij P, Shah O, et al. (2012) Analysis of robotic-assisted laparoscopic pyleloplasty for primary versus secondary repair in 119 consecutive cases. Urology 79: 689-694.

13. Singh P, Dogra PN, Kumar R, Gupta NP, Nayak B, et al. (2012) Outcomes of robot-assisted laparoscopic pyeloplasty in children: a single center experience. J Endourol 26: 249-253.

14. Sivaraman A, Leveillee RJ, Patel MB, Chauhan S, Bracho JE, et al. (2012) Robot-assisted laparoscopic dismembered pyeloplasty for ureteropelvic junction obstruction: a multi-institutional experience. Urology 79: 351-355.

15. Tobis S, Houman J, Thomer M, Rashid H, Wu G (2013) Robot-assisted transumbilical laparoendoscopic single-site pyeloplasty: technique and perioperative outcomes from a single institution. J Laparoendosc Adv Surg Tech A 23: 702-706.

16. Rais-Bahrami S, Rizkala ER, Cadeddu JA, Tugcu V, Derweesh IH, et al. (2013) Laparoendoscopic single-site pyeloplasty: outcomes of an international multiinstitutional study of 140 patients. Urology 82: 366-372.

17. Kaouk JH, Hafron J, Parekattil S, Moinzadeh A, Stein R, et al. (2008) Is retroperitoneal approach feasible for robotic dismembered pyeloplasty: initial experience and long-term results. J Endourol 22: 2153-2159.

18. Cestari A, Buffi NM, Lista G, Sangalli M, Scapaticci E, et al.(2010) Retroperitoneal and transperitoneal robot-assisted pyeloplasty in adults: techniques and results. Eur Urol 58: 711-718.

19. Casella DP, Fox JA, Schneck FX, Cannon GM, Ost MC (2013) Cost analysis of pediatric robot-assisted and laparoscopic pyeloplasty. J Urol 189: 1083-1086.

20. Seideman CA, Sleeper JP, Lotan Y (2012) Cost comparison of robot-assisted and laparoscopic pyeloplasty. J Endourol 26: 1044-1048. 